ISSN $1515-7326, \mathrm{n}^{\circ} 12,1 \mid 2013$, pp. 9 a 30

\title{
Introducción: Notas sobre la comunidad, el perdón y la justicia
}

\author{
Sebastián Torres \\ (Universidad Nacional de Córdoba, \\ Argentina)
}

Haber hecho a un hombre más daño del que cree poder expiar, inclina al ofensor a odiar a la víctima. Porque debe esperar de ella venganza o perdón, cosas ambas odiosas Hobbes, Leviatán, cap. IX

\section{La discusión}

Los términos discusión, polémica, conversación, le caben en diferente medida al intercambio entre Claudia Hilb y Diego Tatián publicado en este número de Discusiones. E1 texto de Hilb, "¿Cómo fundar una comunidad después del crimen? Una reflexión sobre el carácter político del perdón y la reconciliación, a la luz de los Juicios a las Juntas en la Argentina y de la Comisión de la Verdad y la Reconciliación en Sudáfrica", fue leído y discutido en una versión más reducida en las $I I$ Jornadas Internacionales Arendt, realizadas en la Universidad Nacional de Córdoba en noviembre del $2010^{1}$. Allí inició un intercambio con Tatián,

${ }^{1}$ Esa versión fue recientemente publicada con el título "Justicia, reconciliación, perdón ¿Cómo fundar una comunidad después del crimen?" en Lecturas de Arendt. Diálogos con la literatura, la filosofia y la política, J. Smola, C. Bacci y P. Hunziker (edit), Editorial Brujas, Córdoba 2012. Hasta donde sabemos, el texto fue presentado por primera vez en el Simposio Hannah Arendt, III Congreso Colombiano de Filosofia, Cali, Colombia, octubre 2010; también en el Seminari d'Història de la Filosofia, Universidad de Barcelona, España, octubre de 2010; 
origen del texto que aquí se publica, “¿Fundar una comunidad después del crimen? Anotaciones a un texto de Claudia Hilb", leído y discutido, en una mesa junto a Hilb, en el III Encuentro de grupos de investigación en Teoría Política, realizado en la ciudad de Córdoba en octubre del 2012. Intercambio que finaliza con la respuesta de Hilb "Anotaciones a las anotaciones de Diego Tatián". Como podrá apreciarse, los textos que aquí se publican han sido acompañados por sendas discusiones donde han participado muchos colegas; esperamos que su edición amplíe el espacio de estas fundamentales y necesarias conversaciones.

En "¿Cómo fundar una comunidad después del crimen?...", Claudia Hilb propone una doble entrada para analizar los motivos y consecuencias de que en la Argentina se haya obturado la posibilidad para que represores y miembros de las organizaciones involucradas en la lucha armada puedan reflexionar sobre su propia acción y su responsabilidad sobre el Terror de la década del setenta. Una cuestión que Hilb plantea a partir de una revisión sobre la modalidad adoptada en la Argentina para llevar adelante los juicios a los represores. Esa doble entrada es propuesta: a partir de la contrastación con otro caso ejemplar, la labor realizada por Comisión de Verdad y Reconciliación (CVR) creada en Sudáfrica en 1995; analizado conjuntamente con el caso argentino a partir de un conjunto de categorías resultantes de una

y luego en I Seminario Internacional "Nuevos comienzos democráticos: justicia, verdad y reconciliación en Argentina, Uruguay y Sudáfrica", Instituto Gino Germani, Buenos Aires, diciembre de 2011. Este seminario es el resultado del proyecto conjunto de investigación "Nuevos Comienzos: Argentina y Sudáfrica. Un estudio comparativo de la puesta en forma retórica de la democracia". Instituto de Investigaciones Gino Germani (Universidad de Buenos Aires) / Centre for Rhetoric Studies (University of Cape Town) dirigido por Claudia Hilb. Su texto, con el título "Justicia, reconciliación, perdón", ha sido publicado en African Yearbook of Rhetoric 3, 2, 2012, edición a cargo de Hilb y Philippe-Joseph Salazar; en este escrito remite a un texto anterior directamente ligado al tema "Virtuous justice, and its Price in truth in post-dictatorial Argentina", African Yearbook of Rhetoric 2, 1, 2011. Ambos artículos, como otras contribuciones de mucho interés, se encuentran en http://www.africanrhetoric.org. 
Introducción: Notas sobre la comunidad, el perdón....

reflexión sobre la obra de Hannah Arendt, interrogándola sobre el carácter político del perdón, de la responsabilidad y de la reconciliación, donde se pone en juego la relación entre el pensar (la reflexión) y el arrepentimiento, entre el mal y la ausencia de pensamiento. Un recorrido que, como lo indica el título principal de su texto, se orienta por el interrogante sobre la posibilidad de generar las condiciones que hagan posible un "nuevo comienzo" para una sociedad signada por la violencia política. Una de las tesis que Hilb desprende a partir del análisis de la obra de Arendt y la diferencia entre el caso Argentino, centrado en los Juicios y la justicia, y el Africano, centrado en la Verdad y la Reconciliación, es que "es probable que en un caso —el de la Argentina - la resolución haya pagado un precio en Verdad; es probable que en otro caso - el de Sudáfrica - se haya pagado un precio en Justicia": posibilidad que demostrará, principalmente en lo que se refiere al caso argentino. Por supuesto, esta provocadora tesis - en el mejor sentido del término, polémica en relación a lo que considera ha sido el modo dominante en el tratamiento de estas cuestiones en nuestro contexto político e intelectual - es desarrollada a partir de un atento análisis de la obra de Arendt y una detenida argumentación en donde se teje el ejercicio de contrastación entre Sudáfrica y la Argentina.

El escrito de Diego Tatián, como lo refleja su título "¿Fundar una comunidad después del crimen?", se ordena a partir de un cuestionamiento sobre los supuestos que orientan el objetivo anunciado por Hilb, a partir del cual propone cinco anotaciones que tocan a varios de sus núcleos argumentativos, concentrados en un ineludible contrapunto con las afirmaciones ligadas al caso argentino y, solo de manera subsidiaria, referidos a la interpretación que Hilb propone de Arendt y del caso sudafricano. Difícil de resumir, no solo por la variedad de puntos que recorre, sino también por una prosa atenta a la carnadura del lenguaje, donde la pregunta por cómo reconstruir y restituir una vida colectiva no encuentra un límite en la hondura del dolor abierto e inolvidable, sino las condiciones mismas de su comprensión y reparación. Esquivo a hablar de Justicia, sin embargo recorre los difíciles caminos que hacen de la Argentina un lugar que, negando la 
impunidad, ha producido y promovido una profunda reflexión política y una activa militancia, que no ha dejado de afrontar, con todas las dificultades del caso, el problema de la violencia.

Las respuestas de Claudia Hilb - expresadas en ocho breves anotaciones - discuten, aclaran, corrigen y disienten sobre la lectura que Tatián hace de su texto y sobre la posición que toma para responder a él. La respuesta no innova en relación a lo sostenido en el escrito inicial, pero ilustra con mayor claridad su perspectiva. Aunque sucede en muchas polémicas, en ésta en particular y con mayor evidencia parece haber dos opciones para leer el conflicto final de las interpretaciones sobre los hechos y lo dicho: en un caso, se trata de un desacuerdo, encuentro de posiciones diferentes, a veces antagónicas, irreductibles unas a otras; en el otro caso, se trata de un malentendido, en parte por la atribución de tesis no sostenidas o de conclusiones a las que no se ha llegado, en parte porque el abordaje de la cuestión se realiza desde otro punto de vista, que circularía por un carril paralelo sin tocar el argumento central. Quedará a criterio de los lectores valorar el resultado de este intercambio. Pero, más allá de las complejidades propias del texto inicial de Hilb y de ciertos giros argumentales, las respuestas que le suceden carecen de ambigüedades.

Por esta razón, poco queda por introducir, aclarar o contextualizar. Motivo por el cual nos hemos tomado el permiso de continuar con algunas reflexiones que entendemos pueden contribuir a explorar algunos de los desacuerdos presentes en ella así como ampliar algunos de los elementos que han sido expuestos. Partimos de una idea: es dificil sostener que el núcleo del desacuerdo se funda en un malentendido, acaso porque nosotros no podamos sino hablar de lo mismo (lo ha hecho la filosofía, las ciencias políticas, sociales y jurídicas, el cine, las artes plásticas y la literatura), aunque recurramos a lenguajes diversos, propongamos descripciones diferentes, apelemos a fuentes varias y, por supuesto, adoptemos diferentes perspectivas o nos ubiquemos en posiciones contrarias, en muchos casos irreconciliables. Nada de esto, propio de cualquier discusión, pero más aún en este caso particular - que es la forma en que intentamos establecer un trato con la experiencia del terror e indicar los caminos de nuestras esperanzas-, ha 
Introducción: Notas sobre la comunidad, el perdón...

limitado la discusión, la conversación y la reflexión, que conducen nuestro mejor legado de la política democrática.

\section{E1 lenguaje de la "transición"}

Perdón, reconciliación, reparación, memoria, olvido, responsabilidad, promesa, culpa, venganza, arrepentimiento, son algunos de los varios términos que han asaltado el lenguaje ligado al espacio de la denominada "justicia transicional" ${ }^{2}$. Términos que forman parte de nuestra cultura coloquial, la mayoría de ellos poco técnicos tanto para el derecho como para la filosofía, y que sin embargo arrojan luz sobre acontecimientos para los que los lenguajes disciplinares no ofrece respuestas ni inmediatas ni últimas. Términos que conviven con las más conocidas ideas - aunque no más claras y evidentes - de justicia, verdad, ley, pena, Estado, democracia: no anulándolas, sino mostrando su otro costado, sea mostrando sus límites o ampliando sus promesas. Dejar ingresar este lenguaje a nuestras reflexiones sin pretender depurarlas de inmediato de esta terminología heterodoxa ni reducirlo a objeto de una psicología de la catástrofe, nos permite comprender las cuestiones que aquí están en discusión. En algunos casos se hace evidente su contenido moral y ético, a veces religioso; incluso podríamos hablar del retorno de un lenguaje arcaico, mítico, previo a la institución del derecho público y penal moderno. Sin embargo, conviene reconocer que ciertos acontecimientos hacer emerger una densidad propia de nuestro lenguaje, más "antiguo" que la validez o vigencia declarada por la razón crítica, restituyendo a la vez que alterando su ethos social. Por otra parte, muchos de estos términos y sus significados más profundos se han mantenido tras varias de las figuras todavía actuales del derecho y la política - más allá del caso sudafricano-: tal es el caso, por ejemplo, de la paradigmática ley de amnistía ${ }^{3}$, que curiosamente nos

${ }^{2}$ Elster, J., "Memoria y justicia transicional", Memoria y derecho penal, P. D. Eiroa y J. M. Otero (Comp.), Buenos Aires, Di Plácido Editor, 2007.

${ }^{3}$ Loreaux, N., La ciudad dividida. El olvido en la memoria de Atenas, Buenos Aires, Katz, 2008, cfr., principalmente los caps. VI y XI. 
extraña menos que las más recientes leyes denominadas de la memoria ${ }^{4}$, hecho que pone en entredicho la vulgata aparentemente indiscutible de que vivimos en una cultura histórica.

En el intercambio entre Hilb y Tatián podemos encontrar la razón en una "economía del perdón" o considerar que el perdón es política e institucionalmente imposible, pero no podemos ignorar que la cuestión del perdón está ahí, institucionalizado en la CVR sudafricana y públicamente rechazado en la Argentina, pero presente al fin en todos los procesos políticos que enfrentan un pasado violento y criminal ${ }^{5}$. Un pasado que involucra a la sociedad en cuanto tal en una doble referencia: porque cuando es el Estado agente del terror, no es posible imaginar a la sociedad como víctima, a no ser que conservemos una imagen ingenua del Estado como un poder separado de los intereses de grupos sociales; porque el después del terror expone a la sociedad a la imposibilidad de concebirse una comunidad, en un sentido muy diferente - aunque no absolutamente extraño- a las ya conocidas fracturas producidas por la modernidad capitalista (tomemos esta distinción entre sociedad y comunidad como el punto de inflexión entre un agrupamiento de hecho y una expectativa de lo común). La cuestión del perdón, del arrepentimiento, de la reconciliación, su emergencia,

${ }^{4}$ Traverso, E., La historia como campo de batalla. Interpretar la violencia del siglo XX, Fondo de Cultura Económica, Buenos Aires, 2012 (en especial el cap. VIII).

${ }^{5}$ Además de los conocidos escritos de Derrida, J., "El siglo y el perdón", en $E l$ siglo y el perdón seguida de Fe y saber, Buenos Aires, Ediciones de la Flor, 2003; "Justicia y perdón", Entrevista de Antoine Spire en Staccato, 1998 (ambos en Derrida en Castellano http://www.jacquesderrida.com.ar) y Jankélévitch, V., El perdón, Editorial Seix-Barral, Barcelona 1999; uno de los fundamentales trabajos de referencia es Lefranc, S., Politiques du pardon, Presses Universitaires de France, París, 2002 (Políticas del perdón, Ediciones Cátedra-Universidad de Valencia, Madrid, 2004). También puede verse "Aquello que no se conmemora. ¿Democracias sin un pasado compartido?, Revista de Ciencia Politica, vol. XXIII, $\mathrm{n}^{\circ}$ 2, 2003 (http://www.scielo.cl/pdf/ revcipol/ v23n2/art11.pdf) y "Enjeux et limites de la distanciation. Du sujet «réconcilié» à la réconciliation avec l'objet", AFSP-Colloque "Les violences extrêmes", 29 et 30 novembre 2001 (http://www.afsp.msh-paris.fr/archives/ 2001/violencestxt/ lefranc.pdf). 
puede iluminar estas dificultades. No por ello, sin embargo, les da una respuesta. Si bien nuestras instituciones modernas han excluido de sus formas a un importante espectro de los lenguajes con los que enfrentamos los dramas más terribles - y cuya arqueología no resultaría vana-, es también verdad que ciertos acontecimientos han producido un quiebre en el mismo lenguaje de la comunidad, haciendo imposible o inconcebible lo que en otro momento fuera una respuesta, siempre frágil y no necesariamente satisfactoria, pero apoyada en el suelo todavía vivo de una lengua común.

Una cuestión que toca una de las fibras del intercambio entre Hilb y Tatián es, a nuestro entender, la difícil tarea en la que se ve necesariamente envuelta una sociedad para reconstruir y reinventar una comunidad de habla (en sentido material, no trascendental), una lengua propia que pueda dar sentido a sus actos, colectivos e individuales, institucionales, a sus desacuerdos y consensos, un lenguaje que permita una conversación entre generaciones (que naturalmente llegan a un mundo en un estado de la lengua), que de diferentes maneras forman parte de la "lengua nacional". Así, perdón, reconciliación, entre otros términos, expresan algo que va más allá de la posibilidad de su justificación, ética, filosófica o política. Una pregunta posible es si este lenguaje es una respuesta frente al crimen, otra no menos fundamental y quizás anterior, es qué ha producido el terrorismo de Estado con nuestro lenguaje y las experiencias a las que refiere para que estas palabras ya no signifiquen lo que esperaríamos, y de qué manera recrear una lengua que nos permita comprender y actuar.

\section{Justicia y verdad}

La pregunta de Hilb ¿Cómo fundar una comunidad después del crimen?, y los cuestionamientos de Tatián sobre el modo de este interrogante, inscriben la discusión sobre el proceso jurídico sudafricano y argentino también en la difícil e inevitable cuestión de la Justicia, que es donde encuentra sentido la pregunta por la comunidad política, si es que esta pregunta tiene sentido. Tatián lee los juicios como la imperiosa necesidad de activar la justicia, idea que inmediatamente aclara, pues de 
lo que se trata en esta discusión es del castigo, "que en rigor jamás restablece la justicia, ni la produce" sino que busca evitar los efectos insoportables de la impunidad. Por su parte, cuando Hilb contrapone Verdad a Justicia, entendemos que su operación le cabe principalmente también a la idea de justicia penal (es desde esta perspectiva que, para muchos intelectuales, Sudáfrica se transformó en una posibilidad no determinada por la justicia punitiva $\left.{ }^{6}\right)$. Pero ¿cuál es esa otra Justicia que, no asimilable a la justicia penal, funda la comunidad? ¿Cuál es el lazo no mencionado entre esa otra Justicia (que, si diferente a la justicia penal, le corresponde propiamente la mayúscula) y la Verdad? ¿De qué manera se traza ese lazo oculto entre Verdad, Reconciliación (unidos, a su vez, con la culpa y el perdón) y una Justicia en principio no nombrada? ¿Es acaso la Reconciliación el término que ocupa el lugar y da sentido a la Justicia (por ello, no identificado con la justicia penal)? ${ }^{8}$.

Tatián cuestiona esta contraposición entre Verdad y Justicia. No identifica la Justicia con la justicia penal, pero tampoco priva a esta última de una verdad, aquella que se abre en la lucha contra la impunidad, fundada en la mentira, la negación y el olvido. Podríamos discutir aquí si la connotación que posee la Verdad — puesta por Hilb con mayúscula- quiere decir algo más que la verdad fáctica, la

${ }^{6}$ Rivas Pala, P., "Perdón, derecho y política. Consideraciones a propósito de la Truth and Reconciliation Commission", Isonomía, $\mathrm{n}^{\circ}$. 34, abril 2011; Eiroa, P. $\mathrm{D}$, "Memoria y justica en la experiencia de la comisión sudafricana para la verdad y la reconciliación", en Memoria y derecho penal, op. cit.

${ }^{7}$ Imaginamos que Hilb, aguda lectora de Leo Strauss, no ignora el "primer" juicio que funda occidente, el de Sócrates, así como el relato de Platón frente a la democracia posterior a la tiranía de los treinta y la guerra civil. La relación entre verdad, justicia y castigo está desde sus orígenes ligada a la cuestión democrática, la stasis y la reconciliación. En esta dirección, los trabajos de Nicole Loraux y Barbara Cassin que citamos en este texto resultan iluminadores.

${ }^{8}$ Pues incluso previo a la irrupción del lenguaje cristiano del perdón, la justicia estuvo ligada a ciertas formas de la reconciliación comunitaria, fundación que era siempre restitución de un orden perdido a causa de un acto criminal, distribuyendo y retribuyendo premios y castigos $\square$ recordemos aquí Aneximando y Solón. 
Introducción: Notas sobre la comunidad, el perdón...

descripción verídica de los hechos; que es, por otra parte, la verdad que se activa en un proceso penal, por lo cual sería por lo menos difícil transformarla en un término opuesto o, cuanto menos, en términos que se limitan mutuamente (¿hay acaso una Verdad que se sigue de la compresión? ¿esa Verdad, cuyo efecto práctico es el arrepentimiento y la posibilidad del perdón, es la reconciliación?). Así como en Hilb la cuestión del perdón se juega entre dos sentidos, una "economía del perdón" más pragmática y un perdón reconciliador, también la cuestión de la verdad parece jugarse entre dos extremos no siempre reconocibles, entre la verdad de hecho y una verdad ético-política. En la respuesta de Tatián es otra la lógica: allí las verdades de hecho se juegan frente al necesario rechazo de la impunidad. Por esa vía, que reconoce no es la de la Justicia, se abre sin embargo el interrogante social por la Justicia. En la Argentina, la justicia, lejos de ser un Deus absconditus, ha encontrado una expresión situada y una carnadura propia en los Derechos Humanos, cuya extensión de su sentido traza una línea de comunicación entre el pasado, el presente y el futuro.

\section{Fundación}

En el hecho jurídico, la utilización de figuras como el genocidio, el crimen de lesa humanidad, la imprescriptibilidad, así como las discusiones sobre la no retroactividad de la ley, el lugar de los tratados internacionales, entre otras cuestiones no exentas de mayores o menores tecnicismos (como la cuestión de los grados de responsabilidad), han abierto a polémicas cuyo núcleo de fondo es el tipo de justicia que en su aplicación funda la recuperada democracia. En un sentido, esas polémicas no difieren sustancialmente de la aquí presentada, pues sabemos que las decisiones institucionales adoptadas, así como el modo en que son fundamentadas y la interpretación e interpelación pública que se hace frente a ellas determinan en gran medida el horizonte, más o menos limitado, de lo que consideramos posible y deseable.

Cierto es que pasar de discusiones técnicas o teóricas a aquellas donde ingresa el lenguaje del drama social y las expectativas colectivas requiere asumir una perspectiva más amplia que la lógica argumental 
que suele definir las características propias de las disciplinas, sean jurídicas o filosóficas. Hilb, en su respuesta a Tatián, pone límites al alcance que pretendía darle a su reflexión sobre el perdón; sin embargo en su recorrido por la obra de Arendt va indicando diferentes efectos que van más allá de una economía del perdón (ausente en Arendt, como lo indica Tatián) y de su conexión con el recurso jurídico de la amnistía, recuperado de la CVR sudafricana ${ }^{9}$.

Es posible que la amnistía ligada al intercambio por el testimonio propuesta por la CVR sudafricana logre conjurar su más evidente e inmediato significado de olvido, efecto fundado en la dimensión económica del perdón ${ }^{10}$, sin embargo, es la misma lógica económica la que nos hace dudar de su poder para involucrar el lugar más íntimo de la conciencia y la reflexividad sobre los crímenes cometidos. Pero Tatián no se detiene en lo que podría ser una inconsistencia o salto argumental (de la verbalidad a la reflexividad, del testimonio a la toma de conciencia), porque su planteo no trata de proponer otra estrategia para romper la posible falsedad de la relación entre foro interno y foro externo, tarea por demás imposible, a nuestro entender solo franqueable por el supuesto de la confianza y el hecho del reconocimiento, que fundan la promesa mutua: lo que justamente ha sido negado con la eliminación violenta del otro. No es la Verdad lo que se opone inmediatamente a la mentira, sino cierta forma del juramento, que tiene una dimensión y un sentido más vasto y profundo que el juramento

${ }^{9}$ Más concesiva con Arendt que en otra ocasión, aunque no menos aguda, quizás a la cuestión del perdón le caben las mismas ambigüedades y las posibles consecuencias que, según Hilb, se siguen de su reflexión sobre la violencia. Hilb, C., "Violencia y política en la obra de Hannah Arendt", Sociología, año 16, n 47, septiembre-diciembre de 2001 (http://www.revista sociologica.com. $\mathrm{mx} / \mathrm{pdf} / 4702$.pdf.)

${ }^{10}$ Aunque la relación entre memoria y olvido, que ocupa un lugar central en este campo de discusiones, trasciende el problema del conocimiento de las verdades de hecho y los recursos del negacionismo, para entablar una relación - por supuesto compleja - con la justicia. Puede verse Ricoeur, P., La memoria, la historia, el olvido, Fondo de Cultura Económica, Buenos Aires, 2004, en particular el Epílogo, titulado "El difícil perdón", donde interroga las pretensiones de la CVR (pp. 617-621). 
declarativo que antecede a toda palabra en el interior de un proceso judicial: en un caso la figura es "juro decir la verdad", en el otro, "Nunca más", expresión que podría leerse en esa dimensión ampliada no fáctica, como juramento y como promesa ${ }^{11}$, imposible sin embargo sin la incondicional renuncia efectiva a la impunidad. Relación compleja, múltiple y difícil, para nada necesaria ni garantía última de un futuro en el que el terror esté absolutamente conjurado, pues no es un acto - acto judicial de juzgar y condenar, o bien, acto de perdonar - el "origen" de la comunidad democrática, sino un hacer permanente, acompañado de una comprensión ampliada, donde el dolor permanece también porque se descubre permanentemente.

El problema que señala Tatián en torno a la pregunta fundacionalista no es metafísico o epistemológico sino político. Que una comunidad no se funda no solo quiere decir que en un acto paradigmático no se resuelve la relación con el pasado; también puede querer decir que no somos dueños del futuro, en la medida en que los efectos de las acciones son múltiples e indeterminados, se construyen y definen permanentemente. Y esa indeterminación entendemos constituye el trasfondo sobre el que se recorta la forma en que propone redefinir la pregunta, cuya extensión da cuenta de su propia contingencia y de la tarea permanente que demanda al pensamiento, al lenguaje y la acción constituirse entre lo irreversible y lo indeterminado. Por ello también, no es menor señalar el modo en que pensamos la diferencia entre las dos generaciones de los juicios, los de la década del ochenta y los de la primera década del 2000 aún en curso, para (sin desconocer el fundamental sentido de los primeros) alejarse de la lógica fundacional (de por sí refutada por la década de los noventa, como lo sugiere Tatián). Que en los actuales juicios hayan aparecido nuevos testimonios y nuevas generaciones de querellantes muestra que el tiempo, aunque esperanzadoramente orientado a partir de un acto original, no es algo que de ahí en más transcurre direccionalmente: el tiempo también llega.

${ }^{11}$ Debo esta referencia sobre la promesa a la intervención de Carolina Rusca en una mesa dedicada a discutir el texto de Hilb, realizada en el marco de la cátedra de Filosofía Política II de la Escuela de Filosofía de la Universidad Nacional de Córdoba, en septiembre de 2012. 
En el planteo de Hilb se combina una dimensión fundacional de la comunidad con una dimensión pragmática del perdón, original forma de un contractualismo donde se fusiona el más llano interés y la moralidad reflexiva. Un contractualismo que recurre al método inverso del "velo de la ignorancia" rawlsiano, pues cada uno debe saber y reconocer el lugar que ocupa en la escena postdictatorial, exponerse ante los demás y aceptar lo que se siga de ello. Así, da la impresión que el proceso para-judicial (como el de la CVR) y el proceso de constitución contractual del lazo comunitario son enlazados remitiéndonos a un arcano donde las partes conjuran un conflicto originario y son reubicadas en el orden verdadero de la communitas, resultante de un singular tipo de pacto (aunque Hilb no se detenga en este punto, no es posible comprender el pretendido poder instituyente de la Comisión de Verdad y Reconciliación sin considerarla conjuntamente con la nueva Constitución Sudafricana). En el profundo sentido que adquiere la idea de fundación en el planteo de Hilb, podría entenderse que la verdad no se reduce a la recolección de testimonios verídicos; volvemos a interrogarnos, cuál es esa Verdad — con mayúscula - que funda la comunidad. ¿Acaso esa Verdad puede expresarse de manera negativa: no debería haber matado y torturado, no debería haber confundido política y violencia? Aunque devenida relación pragmática, Verdad y Comunidad se ligan de manera positiva en la medida en que se identifican: la verdad es la comunidad. Reconciliarse con la verdad es, a partir del arrepentimiento, restituir una comunidad perdida. Hilb no sostiene directamente esta tesis, pero en la respuesta al escrito de Tatián, donde la dimensión pragmática de su planteo se hace más evidente, se hace más necesario también interrogarse por una operación que sin dudas va más allá de una comparación iluminadora.

\section{Venganza y Justicia}

Entre el amplio espectro del lenguaje que se activa en esta polémica, hay un término no dicho y que creo, podría estar en el fondo del señalamiento de los límites de la justicia penal y del recurso a la idea de perdón: la venganza (término que sí aparece en el proceso sudafricano). 
Introducción: Notas sobre la comunidad, el perdón...

Porque en la larga tradición de estos conceptos, la diferencia fundamental entre la justicia punitiva y el perdón es su supuesta capacidad para interrumpir el círculo violento de la venganza (directamente ligado, por ello, con la amnistía $^{12}$ ). En la relación perdón-venganza la justicia punitiva es puesta bajo la lupa como la continuación de la violencia por otros medios, cuya legitimidad e impersonalidad permitiría una interrupción del círculo de la venganza privada — puesto que la legitimidad así como la impersonalidad son disuasivos de la devolución del daño sufrido: ya no hay justificación colectiva compartida para la venganza-, y sobre todo no hay contra quién vengarse ${ }^{13}$ - pero no necesariamente posibilitaría una interrupción del resentimiento político que la acompaña-. Solo el perdón, entonces, sería un intercambio que, con independencia de la compleja experiencia individual a la que remite (difícil de ser interpretado por fuera del signo cristiano del amor, más allá de las reflexiones de Arendt), no devuelve daño al daño.

No solo en Sudáfrica (en la misma Constitución) se invocó el término venganza para oponerle el conjunto de términos asociados a la posibilidad del perdón, en una escena donde posiblemente encuentre un asidero político real. En la Argentina no ha faltado una "opinión pública" que ha catalogado de venganza a los juicios reiniciados a partir de la década del 2000, no solo porque la justicia siempre puede caer bajo la acusación de parcialidad, sino porque quienes estarían hoy en la justicia serían las "víctimas" que han encontrado su oportunidad para la venganza (diferente a los juicios de Alfonsín ${ }^{14}$ ). Que en el 2004 Néstor

${ }^{12}$ Recomiendo la lectura de este breve escrito de Carl Schmitt, "Amnistía", diario El país, Madrid, 21 de enero de 1977 (momento de plena transición del franquismo), para ver el por lo menos curioso pasaje desde el teórico de la relación amigo-enemigo al discurso de la reconciliación.

${ }^{13}$ Directa o indirectamente, el influyente trabajo de Rene Girard, en particular La violencia y lo sagrado (Anagrama, Barcelona, 1983), está a la base de gran parte de estas interpretaciones.

${ }^{14}$ Raúl Alfonsín (1927-2009), primer presidente constitucional de Argentina luego de la dictadura cívico-militar instaurada entre los años 1976-1983. En 1983 derogó la ley de autoamnistía emitida por el gobierno de facto e impulsó 
Kirchner ${ }^{15}$, en el recordado discurso donde pide perdón en nombre del Estado argentino, afirme que la continuación de los juicios no la motiva "ni el rencor ni el odio, sino la justicia y la lucha contra la impunidad", es un signo de la presencia del problema en la justicia transicional.

No nos vamos a detener para analizar esta pasión, que poco ha sido explorada en las actuales reflexiones sobre la justicia, y que sin dudas está ligada al carácter irreparable y constante de ciertos daños ${ }^{16}$ (y también a la misma historia argentina: basta recordar el asesinato de Ramón L. Falcón ${ }^{17}$ para pensar que la venganza va más allá de las fantasías literarias, que por lo demás no han dejado de ocupar un lugar en el cine y la televisión nacional, sin olvidar también la polémica BayerGiardinelli, entre otras). Sí indicar que en la Argentina, luego de los insoportables crímenes, de las leyes de obediencia debida y punto final, de los indultos, no ha existido un solo caso de "venganza". No nos

el juicio a la Junta militar. En el mismo acto creó la CONADEP (Comisión Nacional sobre la Desaparición de Personas), que un año después presentó el conocido informe titulado Nunca más. Entre 1986 y 1987, por presiones de los sectores militares activos, formuló las leyes de Punto Final y Obediencia debida, que establecieron un límite para los juicios a los criminales de Estado. ${ }^{15}$ Néstor Kirchner (1950-2010), presidente constitucional de Argentina entre el 2003-2007. En 2003 impulsó la derogación de las leyes de Punto final, Obediencia Debida y los indultos otorgados por el gobierno del presidente Carlos Menem (que sucedió a Alfonsín), reactualizando los juicios a los criminales de Estado, que continúan hasta el día de hoy bajo la presidencia de Cristina Fernández de Kirchner.

${ }^{16}$ Me permito referir a Torres, S., "«Mirarse a la cara»: venganza, memoria y justicia, entre Hobbes y Spinoza", Revista Anacronismo e irrupción, vol. 2, N 2 (2012), Instituto de Investigaciones Gino Germani, Universidad de Buenos Aires.

http://revistasiigg.sociales.uba.ar/index.php/anacronismo/issue/current

${ }^{17}$ El coronel Ramón Lorenzo Falcón (1855-1909) fue un militar, policía y político argentino que, como Jefe de Policía de la Capital, estuvo encargado de la represión de las manifestaciones obreras de inicios del siglo XX. Responsable de la represión de la llamada Semana Roja donde fueron asesinados más de 80 manifestantes, unos meses después fue asesinado por un joven obrero anarquista de origen ucraniano llamado Simón Radowitzky. Simón fue condenado a reclusión perpetua y posteriormente indultado por el presidente Hipólito Yrigoyen en 1929. 
hemos visto obligados a comprender actos que, sin dudas condenables, nos deberían llevar a enfrentarnos con una dimensión del dolor que exigiría más que palabras políticamente correctas. Pero, provocadoramente son quienes hacen de los victimarios víctimas los que pueden animarse a mencionar esa palabra. Frente a ella no se ha pronunciado más que una palabra: justicia. Aunque Hilb no menciona la cuestión de la venganza, ni Tatián la incluye directamente en sus consideraciones, creo que estas pocas líneas sobre el tema bastan para considerar que el rechazo al perdón y la amnistía en la Argentina no ha impedido avanzar en una comprensión amplia y profunda de la violencia política, preocupación presente en el texto de Hilb. Perdón y venganza (por el medio que sea) son los dos extremos que nuestra activa militancia contra la impunidad ha rechazado y una muestra de que lo común es posible sin imaginar la necesidad de una escena de reconciliación de la cual dependa la constitución e institución de la democracia argentina.

\section{La promesa democrática y "el fin de los juicios": perspectivas}

En la Argentina no han faltado las polémicas en torno a las diferentes lecturas y posiciones sobre la última dictadura militar, el retorno a la democracia, los juicios a los responsables del Terrorismo de Estado, las políticas de reparación, la memoria reciente, los derechos humanos, la cultura de la violencia y la represión, los legados generacionales, la responsabilidad de las organizaciones armadas, los partidos políticos, el sistema judicial, así como de los grupos de poder civil, y la más general responsabilidad social. Hablo de polémicas porque tanto los estudios más desarrollados como las intervenciones más coyunturales conforman, sin dejar de reconocer sus diferencias, esa compleja e intensa trama de diálogos que han definido a las ciencias sociales y humanas, así como la cultura académica, intelectual y política de nuestro país, desde los años 80 hasta el presente.

No sería difícil reconocer, sin aventurarnos a periodizaciones demasiado esquemáticas, distintos momentos de discusión, cuyos 
problemas y lenguajes puestos en juego - lenguajes políticos, jurídicos, filosóficos y sociales - indican diferencias significativas entre los años ochenta, los noventa y la primera década del 2000, determinados por las políticas del Estado referidas al modo de tratar la historia reciente del Terrorismo de Estado. En la Argentina, los juicios a los responsables de los crímenes han marcado un singular núcleo de discusiones, motivo por el cual el ingreso a la segunda década del 2000 ha abierto el fundamental interrogante por el después de los juicios. Un interrogante que contiene muchas facetas: porque estamos en condiciones de imaginarnos un futuro próximo donde los juicios finalicen y ya no sean estos hechos los acontecimientos movilizadores de nuestra relación con el pasado reciente; porque los juicios actuales serían la última oportunidad para, por la vía judicial, iluminar la parte más oscura de nuestro pasado, a saber, las políticas concretas y los mecanismos más específicos de esa gran operación estatal, que fue el secuestro, tortura, desaparición y asesinato de miles de personas (y, sin duda, detrás de este motivo nadie podría dejar de pensar en el paradero de los cuerpos de las víctimas y de los hijos apropiados); y, más complejo aún, porque la idea de un fin de los juicios, por supuesto inevitable en el más lato sentido cronológico, no deja de ser una idea difusa, en la medida en que los límites de las responsabilidades a juzgar se muevan permanentemente, tanto en el ámbito militar como civil. No podemos dejar de notar que la redenominación "Dictadura cívico-militar" ha resultado para muchos inmediatamente apropiable y para otros una idea inquietante.

No es la primera vez que el motivo de la polémica que aquí se publica aparece en el vasto mapa de las intervenciones sobre los juicios al Terrorismo de Estado y su sentido para la recuperación democrática. Entiendo que la sensible intensidad que puede verse en ella debe leerse a la luz de los actuales juicios y no solo como un debate más donde se renuevan las tensiones propias del tema, en particular cuando se trata de la relación entre víctimas y victimarios.

Claudia Hilb aclara que no asume la perspectiva de las víctimas, le interesa pensar a los victimarios. Intento valorable y difícil, sino imposible. Tatián no parte de las víctimas, sino del daño que portan los 
Introducción: Notas sobre la comunidad, el perdón...

sobrevivientes. Esta diferencia, señalada por Hilb, no podría ser el motivo de los posibles malentendidos. Porque, en todo caso quién sino los familiares de las víctimas serían los primeros autorizados en demandar una "economía del perdón", para poder velar a sus muertos, encontrar a sus nietos y hermanos. Quiénes sino ellos tendrían todo el derecho de anteponer su dolor, incuestionable e inevitablemente propio, a una justicia política para toda la comunidad (en la Argentina, por casos de violencia diferentes, no han faltado las movilizaciones donde el dolor y el odio ocupan el lugar de la justicia, si recordamos lo activado por Blumberg entre el 2004 y el 2006, y la dirección de las reformas penales reclamadas). En Sudáfrica no fueron los familiares sino el Estado quien asumió políticamente una medida donde la economía del perdón, más allá de las víctimas, se inscribe en un horizonte de pacificación social. Lo cierto es que entre una y otra "economía", por más que el método sea idéntico, hay una diferencia.

En la Argentina, los familiares, amigos y compañeros de las víctimas, también víctimas, anteponen una justicia democrática a la economía del perdón-dolor, y encontraron en la memoria y la justicia una respuesta - siempre insuficiente, porque el crimen es irreparable y el dolor inolvidable-, no solo para ellos, sino para todos. Aunque posiblemente sea necesaria una reformulación (como la propone Tatián o de otra manera), en un sentido más directo y básico los familiares cargan sobre sus espaldas con la pregunta de Hilb. "Ni olvido ni perdón", "Memoria, verdad y justicia", son la respuesta a esa pregunta, este es su legado, el después de los juicios. Ser perdonado (no amnistiado) es un don, cuyo efecto para la sociedad es incierto porque remite a una relación de uno a uno, pero no perdonar también puede ser un don que abre a una relación, esta vez política, en un sentido comunitario diferente al enunciado por Hilb (y que creo está presente en la respuesta de Tatián). Un don, que resistiéndose a todo intercambio económico (sea equitativo o extorsivo), se convierte en uno de los signos más fuertes de nuestra democracia. Perdonar genera una obligación individual infinita, pero el don de los que no han aceptado el perdón y han luchado por la justicia y contra la impunidad genera para la comunidad una deuda impagable (si cabe utilizar esta terminología). Esa es una verdad 
de nuestra democracia, y es por ella que no se puede no juzgar a todos y cada uno de los criminales: "Juicio y castigo" no es solo la afirmación de un sistema fundado en la justicia penal que renuncia a pensar otras formas por fuera del paradigma del castigo, de las que todavía no hemos encontrado alternativas (jurídica, ética, política); es una parte necesaria de un más vasto espacio de respuestas que con dificultad y dolor se da una sociedad frente al crimen político que la desgarra (y que no aplica para cualquier tipo de crimen o falta).

¿Reconciliación? ${ }^{18}$ Si algún sentido tiene ese término para abrir a una dimensión práctica de la comprensión es sobre el fondo del reconocimiento, por eso no cabe ser aplicado entre víctimas y victimarios, y quizás ni entre la sociedad y los victimarios, sino entre la sociedad y las víctimas. Un proceso que es muy complejo si no es el Estado el primero que reconoce a las víctimas y responde con la justicia (es allí donde posiblemente - aunque no estoy seguro - tenga sentido la palabra perdón enunciada por un mandatario, siempre que con ella no se de ingreso a la impunidad). El Estado democrático, a partir del 83 y luego del 2004, ha hecho lo que puede un Estado: juzgar. Lo que efectivamente está fuera de la justicia penal, que la sociedad enfrente el dolor y lo irreparable, que se asuma como una comunidad "imposible", en el profundo sentido democrático que porta esta aparente negatividad, es la otra verdad de nuestra democracia. Seguramente esperamos la palabra pública de quienes participaron en la lucha armada —en sentidos no necesariamente idénticos a los que propone Hilb, ligados a la culpa y la confesión; modelo moral a la base (no opuesto) de la judicialización, exista o no una condena- Pero no es de esas palabras que depende causalmente la "fundación democrática"; en todo caso es la espera activa, paciente, comprensiva y no extorsiva, generando todos los espacios posibles para que pueda darse el difícil relato y la conversación, el otro signo de la democracia que hemos podido

${ }^{18}$ Una amplia bibliografía sobre el tema, particularmente sobre Sudáfrica, se puede encontrar en "Conflits et réconciliation", SciencesPo-la bibliothèque, $\mathrm{CB} / \mathrm{CL}$ mars 2008 (http://bibliotheque.sciences-po.fr/fr/produits/ bibliographies/reconciliation/references). 
Introducción: Notas sobre la comunidad, el perdón...

imaginar. Una manera diferente a la explícita y pública promesa de exculpación o de perdón, que no harían más que anticipar lo que se quiere escuchar - el arrepentimiento-, dictarlo antes de hacer posible las condiciones para la escucha de una palabra que no porta menos dolor que otras.

En nuestra imposible comunidad, creo que cada vez más democrática, se trazan las vías para construir lo común, donde el Estado ha ocupado un papel central, haciendo que esa dimensión de la negatividad se exprese de manera afirmativa: hoy los derechos - los que tenemos, los que todavía no tenemos y los que todavía no imaginamosson el signo de la política, y es ese quizás nuestro mejor legado.

\section{Excursus final: Sudáfrica}

¿Por qué Sudáfrica? Mucho se ha dicho sobre la Comisión de Verdad y Reconciliación creada en Sudáfrica en 1995, interés sin duda motivado por su carácter excepcional, frente a los juicios que habrían tomado - con las diferencias de cada caso- el modelo de los procesos de Núremberg. Mucho tiene que ver el momento de este acontecimiento, la actualidad de la violencia colonial finalizando el siglo XX, de una dominación británica que inicia en 1806, reconociéndole una independencia limitada en 1910 y cuya independencia definitiva en 1961 no hizo más que radicalizar la dominación con el régimen del apartheid, hasta el inicio de los procesos de negociación para una salida democrática en la década del noventa.

Claudia Hilb recurre al caso sudafricano para iluminar el proceso argentino, sostiene que no pretende hacer un ejercicio de política comparada ni trasladar el modelo de la CVR ${ }^{19}$. Diego Tatián responde,

${ }^{19}$ Sobre el tema Cassin, B. "«Other à la haine son éternité»: l'Afrique du Sud comme modèle" (http://www.icrc.org/fre/resources/documents/article/ review/review-862-p235.htm) y con el título "Removing the perpetuity of hatred: on South Africa as a model example", en International Review of the Red Cross, vol. 88, $\mathrm{n}^{\circ}$ 862, juin 2006, pp. 235-244. Otras contribuciones pueden encontrarse en la Revue Internationale de la Croix-Rouge, vol. 88, Sélection française, 2006 (http://www.icrc.org/fre/assets/ files/ other/icrc_ 
por un lado, que una comparación más productiva sería pensar el caso argentino junto a las demás respuestas latinoamericanas (Brasil, Paraguay, Uruguay, Chile), verdadero índice de la excepcionalidad argentina, y por el otro, que no podría asegurar que la resolución sudafricana haya logrado una reconciliación social, alcanzado una reflexividad política y, en definitiva, conducido a una sociedad más justa. ¿La Argentina es más justa que Sudáfrica? Hilb se resiste a esa evaluación y le concede a Tatián no haber afirmado eso. Creo que Tatián lo cree, pero ese no es el punto, sino qué es lo que se compara en una comparación y qué es lo que ilumina.

La propuesta de Hilb, que sigue la línea de muchas otras recuperaciones del caso sudafricano en distintos lugares del mundo, no deja de ser fundamental para abrir a una reflexión más amplia sobre nuestro pasado reciente. Es difícil, sin embargo, aceptar su aclaración, dado que los ejemplos (tanto en la "política comparada" como en la filosofía) son modélicos. De ellos se pueden seguir reglas, o bien la exposición de la singularidad del caso, que no permita una traslación simplista y esquemática, pero sí indicar una dirección y un sentido, aquí dados claramente por las ideas de perdón y reconciliación. Ideas que, por otra parte, no han sido ajenas a los discursos políticos en la Argentina, y que convendría también situarlas aquí, ubicar y si es necesario confrontar con sus enunciadores, y no solo tomarlas de Sudáfrica, en su contra-ejemplaridad. Es allí donde se puede comprender mejor por qué, no en la discusión sobre una teoría general del perdón, sino en sus implicancias concretas, en lo que toca a las experiencias individuales y colectivas, fueron y son consciente y

001_0920.pdf). Barbara Cassin, junto a Olivier Cayla y Philippe-Joseph Salazar fueron los editores del imprescindible número de la Revista Le genre humain titulado Vérité, réconciliation, réparation (abril 2004), donde puede encontrarse su ensayo "Amnistie et pardon: pour une ligne de partage entre éthique et politique" así como "Versöhnung, ubuntu, pardon: quel genre?" de Jacques Derrida, entre otros importantes textos. También puede verse "Politiques de la mémoire. Des traitements de la haine", Multitudes, 6, septembre 2001 (http://multitudes.samizdat.net/-Hors-champs-Proceduresd-exception-). 
reflexivamente rechazadas por la sociedad argentina (su rechazo explícito a la amnistía, a los indultos y, en general, al discurso de la reconciliación nacional). La excepcionalidad del caso sudafricano es evidente, porque se sale de la regla de justicia; el caso argentino es menos evidente, porque es el cumplimiento de la regla, y todo lo que se espera se genere a partir de ella, lo que hace a su excepcionalidad.

Es aquí donde cobra relevancia la observación de Tatián y su evocación de las resoluciones sudamericanas, también para echar luz sobre las razones que llevaron a la resolución sudafricana. Porque es verdad que en nuestro continente las leyes de amnistía no adoptaron la lógica de una "economía del perdón": fueron, por decirlo de alguna manera, unilateralmente beneficiosas. Pero iacaso no hay en toda resolución una economía del perdón? ¿Acaso en Brasil no se entendió que la amnistía implicaba un beneficio para la institución de la democracia? ¿Acaso en la Argentina las leyes de obediencia debida y punto final, acertadamente denominadas leyes del perdón, no resultaron de una economía que se entendió beneficiaba a ambas partes? Acaso no exista una lógica económica determinada por la equidad, sino por la imposición de una parte sobre otra con la pretensión de legitimar lo que se supone resultado de un común acuerdo.

Es para nosotros, entonces, también una responsabilidad asumir el modo en que pensamos Sudáfrica (con la misma atención con la que se piensa Auschwitz, notoriamente más presente en nuestra literatura), imaginar qué puede aportar la experiencia argentina a una reflexión sobre Sudáfrica, como sobre Chile o Brasil. Por Sudáfrica, pero también porque esa dirección puede iluminar mejor a la Argentina; porque nacimos como país esclavista, aunque nuestra cultura nacional solo reivindique el discurso del "crisol de razas" y todavía no pueda asumir cabalmente la cuestión aborigen; porque tampoco podemos comprender a Brasil si no podemos pensar en el "apartheid", y el sentido radicalmente diferente que tiene la discusión sobre el perdón si traemos a la reflexión, por ejemplo, el perdón que el presidente Lula da Silva pide a Senegal en un discurso realizado en uno de los mayores puertos esclavistas de África. También, si ampliamos el horizonte, conviene interrogarse por qué es Colombia el país sudamericano donde entendemos ha 
encontrado una mayor recepción el trabajo de la CVR sudafricana, principalmente las ideas de amnistía y reconciliación, para considerar también su ineludible diferencia con el caso argentino ${ }^{20}$.

Hablamos de Sudáfrica sin avanzar en un análisis, conscientes de que para Hilb y Tatián no es el tema en cuestión, para llamar la atención sobre los modos en que la evocamos, porque estos modos también echan luz sobre la manera en que pensamos la Argentina.

${ }^{20}$ La bibliografía colombiana es amplia y dispar, pero puede verse como ejemplo de este interés la mirada de Lecombe, D., "Mobilisations autour d'un modèle de sortie de conflit. La Commission Nationale de Réparation et Réconciliation: une "commission de vérité etréconciliation» (CVR) colombienne?", Raisons politiques, 2008/1, N²9 (http://www.cairn.info/ revue-raisons-politiques-2008-1-page-59.htm). 